UDC 623.463.2

DOI: 10.15587/2313-8416.2015.35894

\title{
THE INFLUENCE OF THE WIND ON THE FLIGHT OF THE UNCONTROLLABLE AIRCRAFTS
}

\author{
(C) V. Makeiev, Y. Pushkarov \\ This article represents research of influence of wind on flight of uncontrollable flying devices. It is offered the method \\ of taking into account influence of permanent wind as well as baffling wind on flight of uncontrollable aircrafts stabi- \\ lized with rotation and empennage \\ Keywords: speed and components of wind, air and flight-path speed, finned missile, missile flight control
}

\begin{abstract}
У статті проводиться дослідження впливу вітру на політ некерованих летальних апаратів і пропонується метод обліку впливу як постійного, так і перемінного вітру на політ летальних апаратів, які стабілізуються як обертанням, так і крилами
\end{abstract}

Ключові слова: швидкість і складові вітру, повітряна і земна швидкість, оперений реактивний снаряд, керування руху снарядів

\section{Introduction}

Exterior ballistics literature considers methods of taking into account the influence of wind on flight of uncontrollable aircrafts [1-3].

But the results of modeling dependence are badly coordinated with tables of gunnery. The registration of wind for empennage missiles on the powered trajectory is very complicated, when it's influence is determinative. Consequently there is a necessity to develop a new ways of taking into account the influence of constant and baffling wind on the flight of the aircrafts with different ways of stabilization.

\section{Formulation of the problem}

The proposal in the literature [1,3] includes that during the modeling of the mathematical dependence for the effect of the wind, the results are badly coordinated with tables of shooting. Some special difficulties rise during the registration of the wind for empennage missiles on the powered trajectory where its influence on the flight of the missiles will be determinative. It's necessary to develop a new ways of taking into account the influence of the constant and baffling wind on the flight of the aircrafts with different ways of stabilization.

\section{Literature review}

There are a lot of methods of taking into account the influence of the wind on the flight of an uncontrollable aircraft in the literature which considers information about exterior ballistics [1-3]. But there are some literature sources which are reviewing the constant wind for empennage missiles $[1,3]$ only, and cross influence of the wind on this types of the projectiles isn't considered. \section{aircrafts}

4. The influence of the wind on the flight of the

Main tasks of studying the influence of wind on flight of shells are: the establishment of the mechanism of the direct influence on the moving shell, to get schemes of the circulation in the atmosphere and the proof of it's efficiency during the solution of the problem.

Wind is the circulation of the air in the atmosphere.

Wind is a vector quantity. As all vector quantities, the wind is measured in direction and speed. The direction of the wind is the azimuth of the horizon $A_{w}$, the place from where the wind is blowing, is measured in degrees. The speed of the wind $\mathrm{W}$ is measured in meters per second. The vector of the wind's speed are usually presented through its constituents $\mathrm{W}_{x}, W_{y}$, and $\mathrm{W} z$. The speed of ascending and descending currents is usually low. They are once or even two times lower than horizontal steams. During the preparation of the information for gunnery we can make a reasonable conclusion, that the changes of the wind's speed in height stays constant during trajectory under the consideration. Chaotic (indigested, turbulent) movement of the wind put in to relative steady horizontal movement of air masses (Fig. 1).

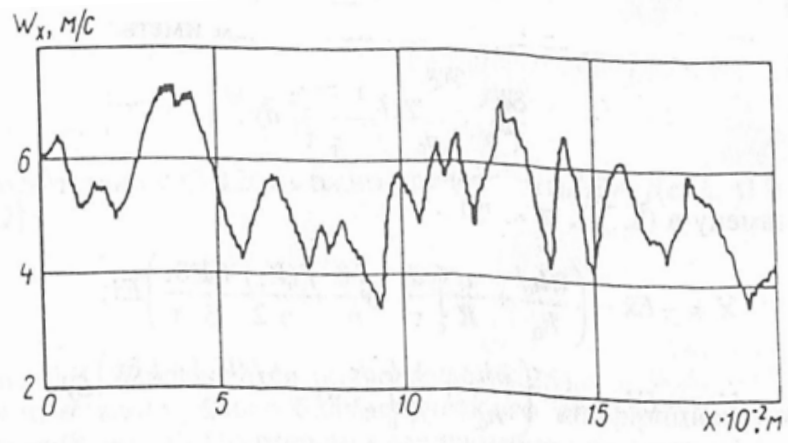

Fig. 1. Variations of the wind's speed in the horizontal direction

It leads to the instability of (changeability) wind, especially sharply reveal near the ground line. It is accepted to distinguish dynamic and thermal turbulence. The dynamic turbulence in the plains are usually reaches the height $1000 \ldots 15000$ meters, but over the see its border even lower. The intensity of the turbulence mainly depends on the wind's speed, roughness of the surface and the stability of the movement of the air masses. It is stronger over cross-country and weaker over the plain and the see. Thermal turbulence reaches rather high altitudes especially in the conditions of the instability of the movement of the considerable amount of air masses and formation of the cumulus. Its intensity depends on the height of the Sun, 
season, and the type of the underlying surface, humidity environment and etc.

In case of need of recoding several (at list two) components of the vector $\mathrm{W}$, its arguments (coordinates and time), give us ground to consider atmosphere where the flight take place as vector (in common case spetiotemporal) field. Time component should be taken into consideration mainly to the air movement low-speed aircrafts. For majority of objects it is possible to consider that vector space field of turbulence is isotropic with in area of space, which investigate the movement of rockets and shells.

Wind and turbulence are accidental factors and during the analyses of the movement of the aircraft they should be taken statistically into the consideration. Hear we shall amount the deterministic substitution, taking into, that the vector of wind's speed,

$$
W(y)=W_{0}(y)+W_{T}(y),
$$

which reflects total movement of air masses is not casual. In the formula (1) $W_{O(y)}-$ a constant component of the wind at height $y$ characterized continuous uniform movement of air masses; $W_{m}(y)$ - turbulent component of wind at height $y$.

The peculiarity of aircraft's movement in the moving atmosphere concludes in that its speed relatively of the Earth and relatively of the moving air masses is different. The speed of the aircraft relatively to the Earth are usually called earth speed, speed relatively to the atmosphere airy. If the earth speed of the shell (absolute) are marked by the vector, speed of the atmosphere relatively to the Earth (the speed of the movable movement - the wind's speed) vector $W$ and air speed of the shell (relative) - vector $V$, so

$$
V_{k}=V+W
$$

the speed of the shell in the movement relatively to atmosphere will be equal.

$$
V=V_{k}-W .
$$

In the projection on the axis in the normal coordinate system OXgYgZg vector equality (3), will have formula

$$
\left[\begin{array}{c}
V_{X g} \\
V_{y g} \\
V_{z g}
\end{array}\right]=\left[\begin{array}{c}
V_{k X g}-W_{X g} \\
V_{k y g}-W_{y g} \\
V_{k z X}-W_{z g}
\end{array}\right] .
$$

If we have constant wind from the last formula and picture 1, we will get

$$
V=\sqrt{\left(V_{k X g}-W_{X g}\right)^{2}+\left(V_{k y g}-W_{y g}\right)^{2}+\left(V_{k z}-W_{z g}\right)^{2}} .
$$

If we take into account only horizontal components of the wind

$$
V=\sqrt{\left(V_{k X g}-W_{X g}\right)^{2}+V_{k y g}{ }^{2}+\left(V_{k z g}-W_{z g}\right)^{2}} .
$$

The Fig. 2 and $u_{k}$ which mean projections of the air and earth speed of the shell on the horizontal plain $\mathrm{OXgZg}$. Using the Fig. 2, we will explain the meaning of the items in the formula (4)

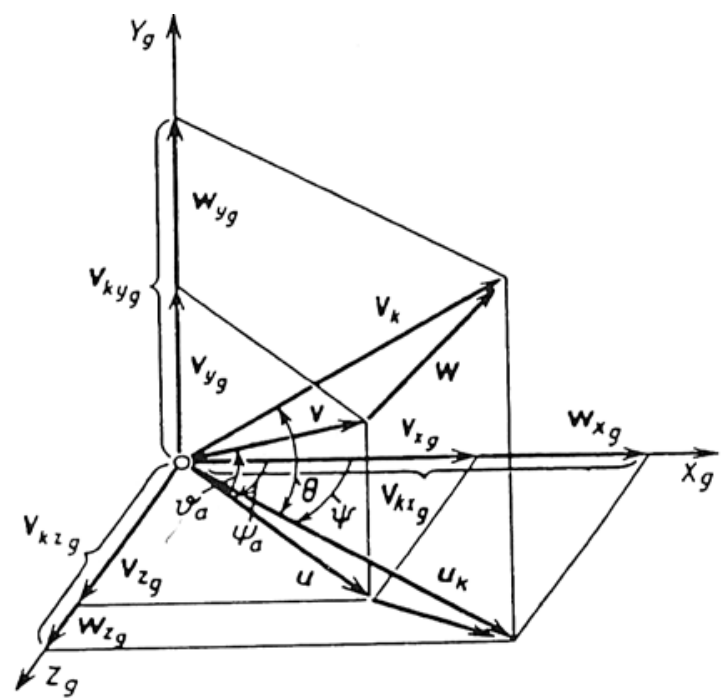

Fig. 2. The scheme of the mutual location of vectors of the earth speed and wind speed

$$
\begin{aligned}
& V \cos v_{a} \cos \psi_{a}=V_{k} \cos \theta \cos \Psi-W_{X g} ; \\
& V \sin v_{a}=V_{k} \sin \theta-W_{y g} ; \\
& -V \cos v_{a} \sin \psi_{a}=-V_{k} \cos \theta \sin \Psi-W_{z g}
\end{aligned}
$$

And we will find the module of the air speed.

$$
V=\left[\left(V_{k} \cos \theta \cos \Psi-W_{X g}\right)^{2}+\left(V_{k} \sin \theta-W_{y g}\right)^{2}+\left(V_{k} \cos \theta \sin \Psi+W_{z g}\right)^{2}\right]^{1 / 2}
$$

So,

$$
\begin{gathered}
\sin v_{a}=\frac{V_{k} \sin \theta-W_{y g}}{V} ; \\
\operatorname{tg} \Psi_{a}=\frac{V_{k} \cos \theta \sin \Psi+W_{z g}}{V_{k} \cos \theta \cos \Psi-W_{X g}} .
\end{gathered}
$$

Mechanism of the influence of the wind on the movement of the aircrafts generally is the solution of the spatial problem taking into account the angles of the attack and sliding, which are defined in relation to the air speed is complicated. That is why during the practice, the action of the longitudinal and side wind are usually taking into consideration separately.

The mutual arrangement of the center of the masses and the center of rocket's pressure are impotent during the determine of direction of the side movement of the missiles at the active area of the trajectory.

The influence of the side wind on the shell forms the additional aerodynamic force $R_{B}$, which appurtenant in the center pressure (Fig. 3). The plumose static stability of the missiles has the center of pressure which is located behind the center of mass, close to empennage, that is why under the influence of the moment from the force $R_{B}$ missile will turn its front part toward to the wind, that its longitudinal axis coincide the vector of air speed. 


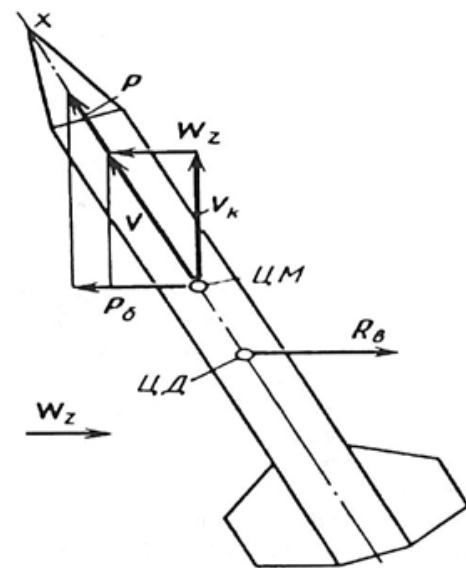

Fig. 3. The scheme of the turning of the uncontrollable missile against the wind ("effect flugera")

At that the side component of traction appears $P_{6}$, which is directed against the wind and in the case $P_{6}>R_{6}$, the shell will also move against the wind. Turbojet shells will move on tha active area of trajectory in the direction of the wind in the result of the drift, complex action of the Magnus's force and the side wind. On the passive area of the trajectory in the case of $P=0$, the missile also as a shell will move in the direction of the side wind. The scheme of the side movement against the wind statically stable plumose missile on the active area of the trajectory under the assumption that the missile is inertia less is on the Fig. 4. We will mark the horizontal projection of the center mass speed in the starting coordinate system through $u_{k}=V_{k} \cos \theta$, the horizontal projection of the speed in the relative movement - through $u_{2}$ according to the Fig. 4 .

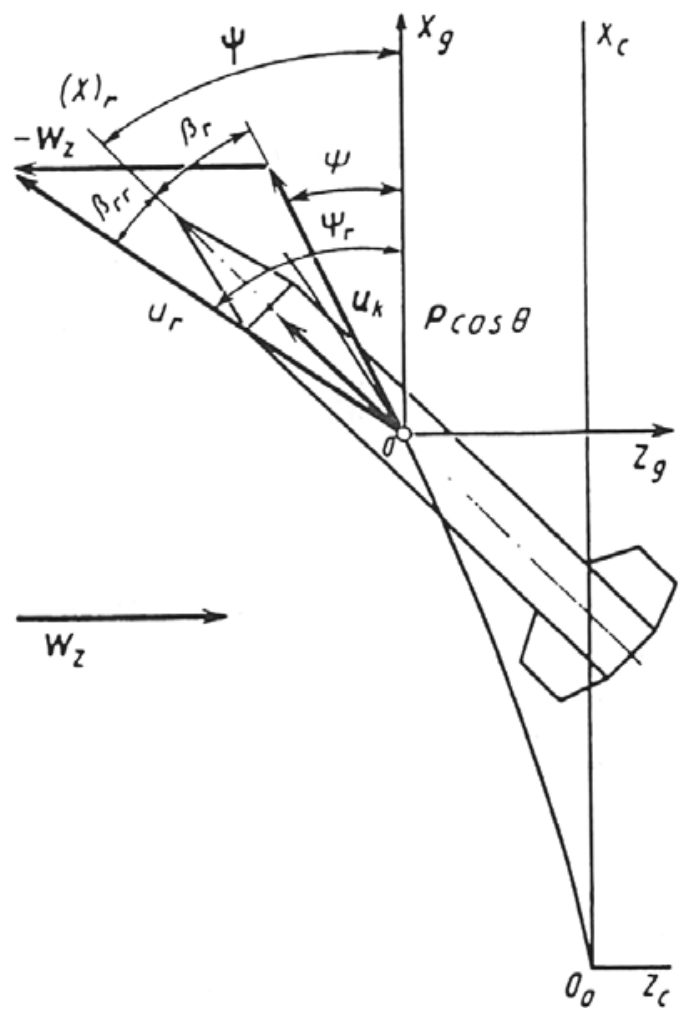

Fig. 4. The scheme of formation of angles of slide during the side movement of the rocket against the wind

$$
\begin{aligned}
& u_{r}=\sqrt{u_{k}^{2}+W_{z}^{2}+2 u_{k} W_{z} \sin \Psi} ; \\
& \cos \Psi_{r}=\frac{V_{k} \cos \theta \cos \Psi}{u_{r}} ;
\end{aligned}
$$

Additional ratio for determination of sliding angle in the relative side movement:

$$
\beta_{r r}=\psi-\Psi_{r} ; \beta_{r}=\beta_{r r} \cos \theta .
$$

There is the scheme of the side movement of stabilized rotation of the missile on the active areas of the trajectory in the case, when the side component of the traction operates in the direction of the wind on the Fig. 5. According to the Fig. 5.

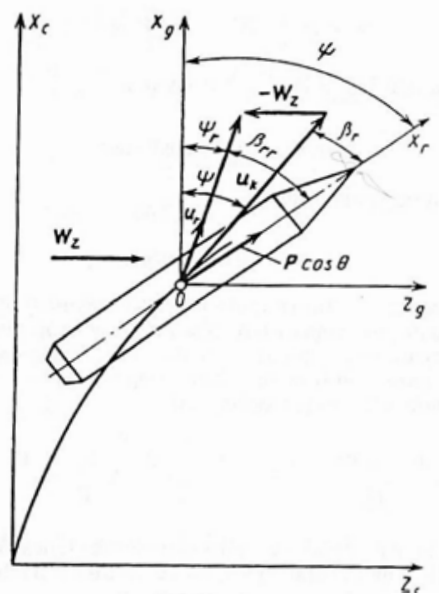

Fig. 5. The scheme of formation of sliding angles in case of side movement of the shell in the direction of the wind

$$
u_{r}=\sqrt{u_{k}^{2}+W_{z}^{2}-2 u_{k} W_{z} \sin \Psi}
$$

From (7) $W_{y g}=W_{X}=0$, we get

$$
\cos \Psi_{r}=u_{r}^{-1} V_{k} \cos \theta \cos \Psi
$$

and additional formula

$$
\beta_{r}=\psi-\Psi_{r} .
$$

Taking into account stable shell as a material point of the changeable masse in consideration of the wind the vector of the traction coincides with the vector of the air speed of the center of mass, we will get cosines of the angles between the direction of the air speed and corresponding axes of start coordinate system.

$$
\frac{V_{r x c}}{V_{r}}=\frac{V_{k x_{c}}-W_{x c}}{V_{r}} ; \frac{V_{r y c}}{V_{r}}=\frac{V_{k y c}-W_{y c}}{V_{r}} ; \frac{V_{r z c}}{V_{r}}=\frac{V_{k z c}-W_{z c}}{V_{r}} \text {. }
$$

If we define frontal resistance using ballistic coefficient $c$ and function $G\left(V_{\tau}\right)$., so the value can be calculated with the help of speed $V_{r \tau}$.

$$
E_{r}=c H_{\tau}(y) G\left(V_{r \tau}\right) .
$$

For the shell with constant mass, the system of the equation, which takes into account the influence of the wind, we can wright as a common system

$$
\begin{aligned}
& \ddot{x}=-E_{r}\left(\dot{x}-W_{x}\right) ; \\
& \ddot{y}=-E_{r} \dot{y}-\mathrm{g} ; \\
& \ddot{z}=-E_{r}(\dot{z}-W z) .
\end{aligned}
$$

Using (6) we can get

$$
V r=V_{k} \sqrt{1+\frac{W^{2}}{V_{k}}-\frac{2 \dot{x} W_{x}}{V_{k}^{2}}-\frac{2 \dot{z} W_{z}}{V_{k}^{2}}},
$$


where:

$$
\begin{gathered}
W=\sqrt{W_{x}^{2}+W_{z}^{2}} ; \\
V_{k}=\sqrt{\dot{x}^{2}+\dot{y}^{2}+\dot{z}^{2}} .
\end{gathered}
$$

The speed of the shells with the constant mass is usually faster than the speed of the wind. Throw back in to (19) term $W^{2} / V_{k}^{2}$ and $W^{2} / V_{k}^{2}$ small in compared with one, and also factor the simplified function (19) in the binominal series and disdain the terms which consist relation between the projection of the wind's speed $W_{x}$ and speed $V_{\kappa}$ which are bigger.

$$
\begin{gathered}
V_{K}=V_{K}-W_{X} \dot{x} V_{K}^{-1} \\
G\left(V_{r \tau}\right)=\left[1-W_{X} V_{K}^{-2} f\left(V_{k \tau}\right) \dot{x}\right] \mathrm{G}\left(V_{k \tau}\right) \\
E_{r}=E\left[1-W_{x} V_{x}^{-2} f\left(V_{k \tau}\right) \dot{x}\right]
\end{gathered}
$$

Where $f\left(V_{k \tau}\right)$ we can define it with the help of $f_{(V k \tau)}=G^{\prime}\left(V_{\tau}\right) G^{-1}\left(V_{\tau}\right) V_{\tau}$

Put under $E_{r}$ into (18) and disdain the quantity of the second infinitesimal order, we can receive the formula which takes into account the influence of the wind of the flight of the plumose and rotatable shells $[4,5]$.

$$
\begin{aligned}
& \ddot{x}=-E \dot{x}+E\left[1+V_{k}^{-2} f\left(V_{k \tau}\right) \dot{x}^{2}\right] W_{x} ; \\
& \ddot{y}=-E \dot{y}+E V_{k}^{-2} f\left(V_{k \tau}\right) \dot{x} \dot{y} W_{x}-g ; \\
& \ddot{z}=-E\left(\dot{z}-W_{z}\right) .
\end{aligned}
$$

\section{Approbation of the research results}

Information in this article is used to produce mathematic models of the movement of empennaged missiles, which can be recommended to make up the firing tables with the shells of this type $[6,7]$.

\section{Conclusion}

1. This article offers dependence accounting influence of wind on flight of uncontrollable flying devices stabilized with rotation and empennage.

2. Using combined equation of movement of center of mass of flying devices allows to solve tasks concerning calculation of windage both on active and passive phase of trajectory.

\section{References}

1. Chernozubov, A. D. Exterior ballistic part I [Text] / A. D. Chernozubov, V. D. Kyrichenko et. al. - Military publishment, 1954. $-463 \mathrm{p}$.

2. Chernozubov, A. D. Exterior ballistic part 2 [Text] / A. D. Chernozubov, V. D. Kyrichenko. - Military publishment, 1954. $-495 \mathrm{p}$.

3. Ravdin, I. F. Military ballistic [Text] / I. F. Ravdin. Military publishment, 1956. $-291 \mathrm{p}$.

4. Dmytrivsky, A. A. Exterior ballistic [Text] / A. A. Dmytrivsky, A. N. Lysenko. - Engineering, 1991. - 640 p.

5. Burlov, V. V. Ballistic of the barrel system [Text] / V. V. Burlov, V. V. Grabin, N. M. Moncheno and others. - Engineering, $2006-459 \mathrm{p}$.

6. Ravdin, I. F. Military ballistic of uncontrollable projectiles and shells [Text] / I. F. Ravdin. - Military publishment, $1973-184 \mathrm{p}$.

7. Makeev, V. I. The determination of the set for firing is based on the solvation of the differential set of equations of aircraft movement. Publishing company: The systems of the armory and military technique [Text] / V. I. Makeev. - Kharkov State University of air forces. - KhSUAF, 2013 - P. 34-38.

\section{References}

1. Chernozubov, A. D., Kyrichenko, V. D. et.al. (1954). Exterior ballistic part I. Military publishment, 463.

2. Chernozubov, A. D., Kyrichenko, V. D. (1954). Exterior ballistic part 2. Military publishment, 495 .

3. Ravdin, I. F. (1956). Military ballistic. Military publishment, 291.

4. Dmytrivsky, A. A., Lysenko, A. N. (1991). Exterior ballistic. Engineering, 640

5. Burlov, V. V., Grabin, V. V., Moncheno, N. M. et. al. (2006). Ballistic of the barrel system. Engineering, 459.

6. Ravdin, I. F. (1973). Military ballistic of uncontrollable projectiles and shells. Military publishment, 184.

7. Makeev, V. I. (2013). The determination of the set for firing is based on the solvation of the differential set of equations of aircraft movement. Publishing company: The systems of the armory and military technique. Kharkov State University of air forces, KhSUAF, 34-38.

Рекомендовано до публікациї доктор технічних наук, дочент Воронько В. В. Дата надходження рукопису 02.12.2014

Makeyev Vasiliy, PhD, associate professor, Military department, Sumy State Unversity, Rimskogo-Korsokova st. 2, Sumy, Ukraine, 40000

E-mail: info@kxp.sumdu.edu.ua

Pushkarev Yriy, Candidate of Military Sciences, associate professor, Military department, Sumy State University, Rimskogo-Korsokova st. 2, Sumy, Ukraine, 40000

E-mail: $\underline{\text { Mechta-58@,mail.ru }}$ 